\title{
ASSESSMENT OF CONSTRUCTION OPERATIONS PRODUCTIVITY RATE AS COMPUTED BY SIMULATION MODELS
}

\author{
Hani Alzraiee \\ Tarek Zayed \\ Osama Moselhi \\ Concordia University \\ 1455 De Maisonneuve West, \\ Montreal, QC, H3G 1M8, CANADA
}

\begin{abstract}
Modeling and simulation tools are used to assist decision-makers to predict essential parameters such as completion duration and productivity rate of construction operations. Two approaches are used, process simulation and system simulation. The first compute parameters based on processes interaction while the second focuses on the complex relationship among project components and their impacts. This paper presents an assessment to simulated project completion duration and productivity rate under traditional Discrete Event Simulation (DES) and modified traditional simulation technique. The evaluation is based on a simulated real case study. The process elements of the case were simulated using (DES) while system elements were simulated using System Dynamics (SD). A significant difference in productivity rate and duration was noticed between the base DES model and the impacted model. The argument presented about the credibility of simulation model outcomes highlight the pitfalls of simulation models and the measures that should be endorsed.
\end{abstract}

\section{INTRODUCTION}

Modeling and simulation tools are an essential part of understanding system behavior. They provide a ground where elements of the project or system can be assembled and allowed to interact in the virtual world within a safe and controlled environment (AbouRizk 2010). Several methods, such as mathematical modeling, and simulation have been developed to predict the behavior and outcomes of certain parameters (e.g., cost, time, productivity rate, etc.) that are associated with construction operations. However, every method has its pros and cons. The superiority of simulation over mathematical modeling lies in the ability to simulate the complex logic inherent in construction operations. Such benefits have been documented by many researchers. Despite these benefits, simulation has not been used to its maximum potential in modeling and simulating construction operations (Huang and Halpin 1994; Tucker et al. 1998). This is mainly due to the widespread skepticism among construction industry practitioners to trust simulation analyses. Construction planners and analysts, who are typically well familiar with the actual construction operations, are reluctant to base their decisions solely on the statistical text and graphical chart output provided by most simulation systems (Ioannou and Martinez 1996). This constitutes what has become known as the "black-box effect" and is a major impediment in validating and verifying simulation models. The resulting lack of credibility hinders the widespread use of simulation in the construction industry (Kamat and Martinez 2001). In addition, such tools address one side of the construction operations and totally neglect important aspects. The issue of main concern is the ability of the simulation model to present a real picture of the actual status of construction operations. This includes accounting for the sur- 
rounding environment that influences the real behavior. Capturing the real picture is a challenging task, due to the turbulence and high dynamics of construction.

Productivity rate of construction operations is an important parameter that might change management policies and decisions. Its improvement depends on understating the work process and the impact of variety of factors. In terms of simulation approaches, the problem that requires deployment of simulation tool can be addressed from two perspectives, process simulation, and system simulation. Howell and Koskela (2000) have pointed out that, in reality, relationships between activities are complex, and activity boundaries are loose; thus, it is inaccurate to define a process without addressing the seemingly insignificant factors related to this process. These factors, in fact, control the behavior; consequently, the primary objective of the simulation model presented in this paper is to incorporate these factors into construction operations simulation, and closely monitor their impacts.

The objective of this paper is to assess and enhance productivity rate and completion project duration generated by DES models. It tends to investigate whether construction project simulation models capable of generating realistic output or not. To fulfill this objective, a short review of the methods used to predict the outcomes of construction projects in the virtual world is conducted. Then, field data of real construction project (earthmoving operations) is collected, modeled, and simulated using DES and SD methods. Finally, discussion of the results and conclusions are presented.

\section{BACKGROUND}

Simulation tools are used to model construction projects in virtual world to predict productivity rate and completion duration. However, the main question that arises is about the credibility of such figures. Traditionally, construction projects are of heterogeneous nature and involve many interactions externally and internally. Consequently, construction operations behavior is a resultant of the interaction of these diverse elements. This requires a flexible simulation tool that could deal with such complexity, as single simulation tool seems to address specific level of complexity.

In general, productivity rate is defined as an amount of work scope accomplished within a certain period. In reality, however, fostering productivity cannot be accomplished with only speed and harder work without considering optimum work practice (Banik 1999). Productivity rate improvement relies on an understating of the work process and the impact of various factors on productivity (Choy and Ruwanpura 2006). These two preconditions for productivity improvement and subsequently prediction, categorized the modeling and simulation techniques as process focus and system focus. Under those two categories several simulation applications have been developed, however, the usage of these applications was very limited in professional field. A believed reason for that is the inability of simulation models to yield realistic results. For instance, the process modeling (e.g., discrete event simulation approach) focuses on the logical sequence among the operation process or tasks, because process modeling perceives productivity rate is determined by the process that controls the logical relationship among operation tasks, and how best processes utilize resources. On the other side, system modeling (e.g., system dynamic approach) focuses on the complex relationship among project components, and in many occasions, organization structure is considered. This provides an opportunity for addressing the problem from a global perspective. In system modeling, productivity is determined by process environment, while process itself is not involved in the modeling, which is one of the main pitfalls of system modeling tools.

Through reflecting the aforementioned discussion on the current practice of construction operations simulation, it can be noticed that DES simulation is used at the tactical level of projects, which means process modeling. While SD is used to model the global aspects of the construction projects similar to system modeling. These two types of models individually fail to incorporate the complicated feedback process among various components of construction project. For example, earthmoving operations are usually viewed as loading, hauling, and dumping processes when workforce, material, and resources are available. From process modeling and simulation perspective, earth is moved when recourses are available for this process. However, many other factors affect the earth hauling and dumping process, such as 
weather, equipment condition, operator skill, new work force hiring, and overtime. These factors play an essential role in determining the level of productivity rate and the time taken to accomplish the scope of work. These two types of modeling and simulation are addressed in the coming sections with simulation models developed for real construction data. The research methodology is described through explaining the development of the simulation models.

\section{METHODOLOGY}

The method followed to achieve the paper objective mainly relies on conceptual modeling. Such models provide better knowledge and understanding of the subject matter they represent. In simulation, it is simply easy to believe that the conceptual model (mental model) of a project is correct and reflects the real system behavior in real world. However, when this conceptual model is implemented and carefully tested, incorrect fundamental issues come up. Therefore, from the conceptual model, the influential elements that generate the real system behavior are identified. The conceptual model of this study is a relationship between process parameters, system parameters, and surrounding environment parameters as demonstrated in Figure 1. The interactions of these parameters generate the project real outcomes such as productivity rate and completion duration. In construction, ideal productivity rate is calculated by outputs produced by a unit time as shown in Equation (1):

$$
\text { Productivity Rate I = Output/Time. }
$$

However, previous studies have proven that productivity rate estimation shown in Equation (1) represents ideal situation where no provision is made for the numerous unexpended factors occurring during the course of construction operations. Thus, realistic productivity rate can be calculated by Equation (2):

$$
\text { Productivity Rate } \mathrm{R}=\text { Output/Time x P }
$$

where Output is volume of accomplished and accepted work and P is defined as an impaction value, between 1 and 0 , and represents the magnitude of the parameters affecting productivity rate, such as weather, skills, equipment condition, etc. In process simulation approach, the value of $\mathrm{P}$ is considered $100 \%$ since process simulation focuses only on the interactions of processes at a narrow perspective. Now, the challenge is how to calculate the value of $\mathrm{P}$, and inject it into the process simulation model. The method that quantifies $\mathrm{P}$ value should be able to link all factors affecting outcomes of construction operation as these factors in reality are mutually linked. SD modeling (Forester 1961) is powerful in modeling mutually linked varaibls or factors and quantifying them. Therefore, SD simulation is utilized to model these factors and inject them in DES model to present realistic project productivity rate and duration. To summarize, first DES model( process model) is developed to calculate construction operation productivity rate and duration, secondly, factors affecting productivity and duration are modeled by using SD method (system model approach) to calculate $\mathrm{P}$ value. Thirdly, value of $\mathrm{P}$ is injected into the DES simulation model to see how the productivity rate and duration changes form ideal to realistic values. 


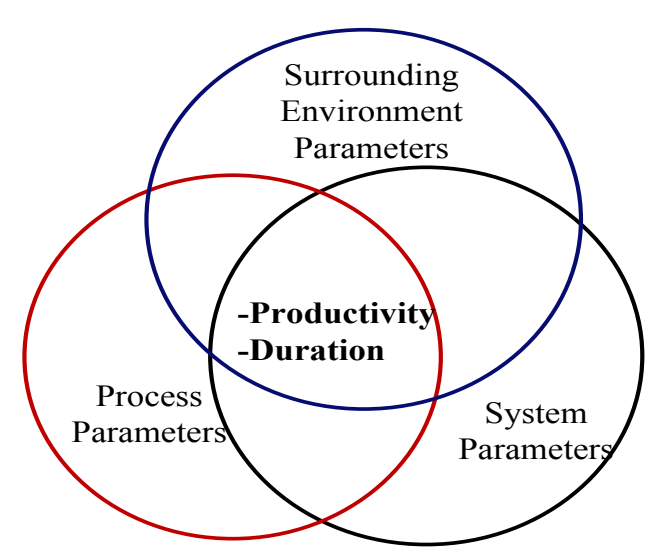

Figure1: Conceptual framework of estimating productivity rate and duration.

\section{CASE STUDY DATA}

\subsection{Scope of Work}

The assessment of productivity and completion duration was performed using a real case study form the construction sector. The earthmoving operations that involved backfill operations in a dam construction were modeled and simulated. The total scope of work was backfilling and compacting 6.3 million $\mathrm{m}^{3}$ of soil classified as: 1) compacted moraine (clay); 2) granular (sand and gravel); and 3) rock, as demonstrated in Table 1. The backfill operations involved process such as loading, hauling, dumping, spreading, and compacting of the soil.

Table 1: Scope of work.

\begin{tabular}{llllllll}
\hline Soil Type & $\begin{array}{c}\text { Stage 1 } \\
\mathrm{m} 3\end{array}$ & $\begin{array}{c}\text { Stage 2 } \\
\mathrm{m} 3\end{array}$ & $\begin{array}{c}\text { Stage 3 } \\
\mathrm{m} 3\end{array}$ & $\begin{array}{c}\text { Loose } \\
\text { Density } \\
(\mathrm{t} / \mathrm{m} 3)\end{array}$ & $\begin{array}{c}\text { Bank } \\
\text { Density } \\
(\mathrm{t} / \mathrm{m} 3)\end{array}$ & $\begin{array}{c}\text { Load } \\
\text { Factor } \\
\%\end{array}$ & $\begin{array}{c}\text { Total of Soil } \\
\mathrm{m} 3\end{array}$ \\
\hline Rock & 192,700 & $3,209,400$ & $1,602,900$ & 1.66 & 2.73 & 80 & $5,005,000$ \\
Granular & 14,500 & 286,500 & 139,000 & 1.72 & 1.93 & 90 & 440,000 \\
Moraine & 29,200 & 555,900 & 269,900 & 1.66 & 2.02 & 100 & 855,000 \\
Total & 236,400 & $4,051,800$ & $2,011,800$ & 1.6 & 2.4 & 100 & $6,300,000$
\end{tabular}

\subsection{Fleet Configuration and Duration of Processes}

The fleet configuration used to execute the project scope is shown in Table 2. The information pertaining to equipment was obtained from the manufacturing specification manual of Caterpillar (2010). The fleets of equipment consisted of three types of haulers (777D, 773D and 769C) served by three types of loaders (992G, 990SII, and 988F) respectively. Soil spreading and compacting operations were performed using a spreader D8R and a compactor CS-583C respectively. Length, total positive resistance, and negative resistance for each road segment used by trucks to haul soil to the dumping zone and return to the loading zone were calculated from the site location maps. The travel times of haulers under loaded and unloaded conditions, corresponding to certain speeds were calculated using manufacturer's charts (Rimpull-SpeedGradeability and Brake Performance Charts), total resistances, and road segment lengths. Duration times needed by loader to load a specific truck were calculated using loader specification charts and tables, and 
same procedures were followed to calculate time durations for spreaders and compactors. A triangular probability distribution was considered for the process durations (loading, hauling, returning, spreading, and compaction) and a uniform distribution for the dumping activity was selected. A triangular distribution considers the maximum, most likely, and the minimum, thus it is more representative of reality.

Table 2: Fleet configuration and characteristics.

\begin{tabular}{|c|c|c|c|c|c|c|c|}
\hline $\begin{array}{l}\text { Soil } \\
\text { Type }\end{array}$ & $\begin{array}{l}\text { Hauler } \\
\text { Model }\end{array}$ & $\begin{array}{l}\text { Loader } \\
\text { Model }\end{array}$ & $\begin{array}{l}\text { Hauled } \\
\text { Soils } \\
\text { (ton) }\end{array}$ & $\begin{array}{l}\text { Triangular } \\
\text { Distribution } \\
\text { of Loading } \\
\text { Time } \\
\text { (m) }\end{array}$ & $\begin{array}{l}\text { Triangular Dis- } \\
\text { tribution of } \\
\text { Hauling Time } \\
\text { (m) }\end{array}$ & $\begin{array}{l}\text { Triangu- } \\
\text { lar Dis- } \\
\text { tribution } \\
\text { of } \\
\text { Dumping } \\
\text { Time (m) }\end{array}$ & $\begin{array}{l}\text { Triangular Dis- } \\
\text { tribution of Re- } \\
\text { turn Time } \\
\text { (m) }\end{array}$ \\
\hline Rock & 777D & $992 \mathrm{G}$ & 81.67 & $\begin{array}{l}(3.94,4.15, \\
4.57)\end{array}$ & $(4.3,4.53,4.98)$ & $(1.9,2.2)$ & $(3.17,3.34,3.67)$ \\
\hline Moraine & $773 \mathrm{D}$ & 990 SII & 45.82 & $(3.01,3.2,3.32)$ & $\begin{array}{l}(19.47,20.5, \\
22.55)\end{array}$ & $(1.6,1.9)$ & $\begin{array}{l}(16.71,17.59 \\
19.35)\end{array}$ \\
\hline Granular & $769 \mathrm{C}$ & $988 \mathrm{~F}$ & 34.36 & $(2.3,2.42,2.5)$ & $\begin{array}{l}(30.6,32.34, \\
35.57)\end{array}$ & $(1.3,1.5)$ & $\begin{array}{l}(25.85,26.51, \\
29.16)\end{array}$ \\
\hline
\end{tabular}

\section{SIMULATION MODEL}

In order to present an assessment of the simulation model outcomes, the first goal was to define the elements that generate the real behavior. The definition of these elements was established by decomposing the project from top to bottom into modeling elements as shown in Table 3. The decomposed elements are emerged from different decision management levels; therefore, more than one simulation method was used for an accurate representation of the project. For instance, elements shown in Table 3 arise from operation and strategic/context levels, thus DES and SD modeling are used respectively. The combination of both models results in a hybrid DES_SD simulation model. The SD model is developed in such away to have interface points where DES values and rates are input into the model. For more details about the integration and synchronization of the DES and SD models in the hybrid environment, the reader may refer to Alzraiee et al. (2012a) and Alzraiee et al. (2012b). The appropriate simulation method that corresponds to each element was selected based on the unique characteristic of each element. Thereafter, simulation of these elements comprised three stages. The first stage was developing discrete simulation models for process level elements. Since discrete models focus on process level and generate ideal results, these models will be called Base Model (BM). The BM represents the benchmark outcomes that are compared later with actual project data or with upgraded discrete simulation models by involving system level elements. The scope of work involved nine operations, thus, nine discrete simulation models were developed using EZStrope (Martinez 1996). The execution of these operations in reality was carried out concurrently with a lag time (as soon as a current operation accomplishes 50\% of its scope, the successor operation starts), and executed using different fleet combinations (trucks-loader). These two constraints are considered the main limitations of discrete application in construction. However, these two limitations were overcome by utilizing SD modeling (Vensim software) and as expected, the simulation model behaved similar to discrete model as shown in Figure 2.

The Gantt chart shown in Figure 2 shows the nine operations that were involved in the backfilling as generated by the BM. The figure indicates a successful concurrent planning based on the real situation $(50 \%)$ and project completion duration that is similar to durations generated by DES models. This represents a successful validation of the BM. The second stage was developing a simulation model that considers the system elements and surrounding environment factors to compute the P value. Figure 3 demon- 
strates the causal-effect feedback loops that address the dynamic problem of the earthmoving operations project. Different reinforcing and balancing loops are shown. From these loops, the SD model was developed. For instance, the policy of overtime when considered, it will cause fatigue and reduction in the productivity rate of the fleet and operators. This value is called $p$ value resulted from overtime strategy. Similarly, the adverse effects of weather, rework, and schedule pressure where modeled and their respective $p$ values are calculated. The total impact of all $p$ values is represented in the P. The third and last stage involved injecting the $\mathrm{P}$ value into DES models outcomes through the SD model interface points. The new model, emerging from upgrading DES model, is called Factors Loaded Discrete Model (FLDM.)

Table 3: Summary of the simulation model elements.

\begin{tabular}{|c|c|c|}
\hline Operations & Level Process Elements & System Level Elements \\
\hline Rock11* & \multirow{9}{*}{$\begin{array}{l}\text { Loading } \\
\text { Hauling } \\
\text { Dumping } \\
\text { Return } \\
\text { Spreading } \\
\text { Compacting }\end{array}$} & \multirow{9}{*}{$\begin{array}{l}\text { Road condition, over- } \\
\text { time, rework cycle, soil } \\
\text { type, operator skill, } \\
\text { weather condition, over- } \\
\text { time, and Schedule pres- } \\
\text { sure. }\end{array}$} \\
\hline Granular12 & & \\
\hline Moraine13 & & \\
\hline Rock21 & & \\
\hline Granular22 & & \\
\hline Moraine23 & & \\
\hline Rock31 & & \\
\hline Granular32 & & \\
\hline Moraine33 & & \\
\hline Simulation Method & Process Modeling & System Modeling \\
\hline
\end{tabular}

*Rock 11 (stage I, scope of rock 1)

\section{Base Model}

Scope Task is Active D[Scope]

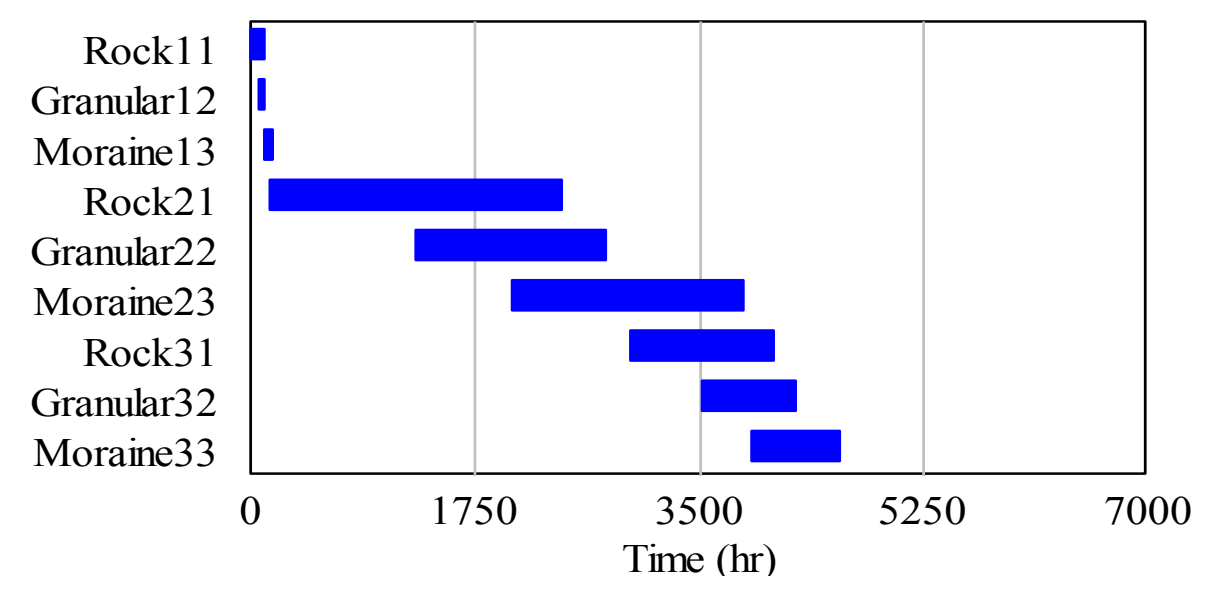

Figure 2: Gantt chart of operations simulated discretely. 


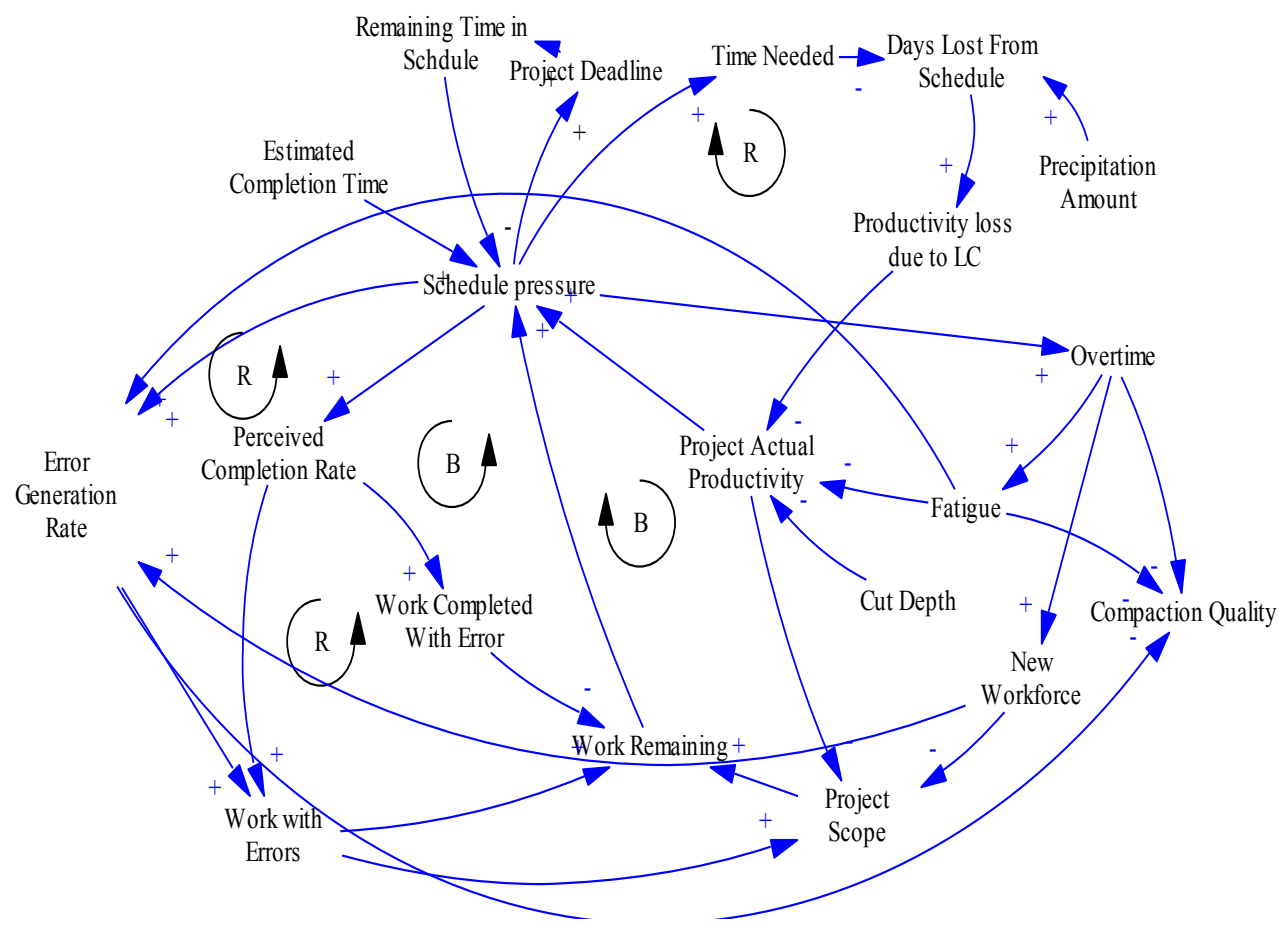

Figure 3: Causal-effect feedback processes addressed in the model.

\section{6}

\section{DISCUSSION OF RESULTS}

\subsection{Completion Durations}

The results of simulated operations such as productivities of dumping processes, spreading processes, and compaction processes, in addition to completion durations are shown in Table 4. The productivity rate was generated as probability normal distribution. These results represent the BM where no influence of factors except process level elements. In this case, the $\mathrm{P}$ value identified is $100 \%$. The total duration of the project (sum of involved operations) was 8504 hours, and when an overlapping of $50 \%$ between operations is considered, the project duration is 4620 hours.

In the second stage when surrounding factors identified in Table 3 (system level elements) are loaded on the BM to result in FLDM, the project completion duration was extended to 6684 hours. This represents a significant increase of $44.6 \%$ in project completion duration. Follow-up of actual data of the elements involved in the modeling process suggested that this percentage represents what had been actually experienced in the project execution. For instance, the precipitation rate (weather factor) is an essential factor to be considered in earthmoving project since it significantly affects the environment of work, and this factor has contributed to a loss of 1715 hours from the work schedule. A full comparison between operation durations computed by BM and FLDM is shown in Table 5.

\subsection{Productivity Rate}

In term of productivity rate as demonstrated in Figure 4 and Table 4, the discrete model resulted in an ideal productivity rate of dumping, spreading, and compactions. For instance, the dumping productivity rate for Rock11 in the BM was 1393 ton/hour with a standard deviation of 35 ton/hour while average dumping productivity rate as computed by FLDM was 1217 ton/hour. 
Alzraiee, Zayed, and Moselhi

Table 4: DES models outputs (BM).

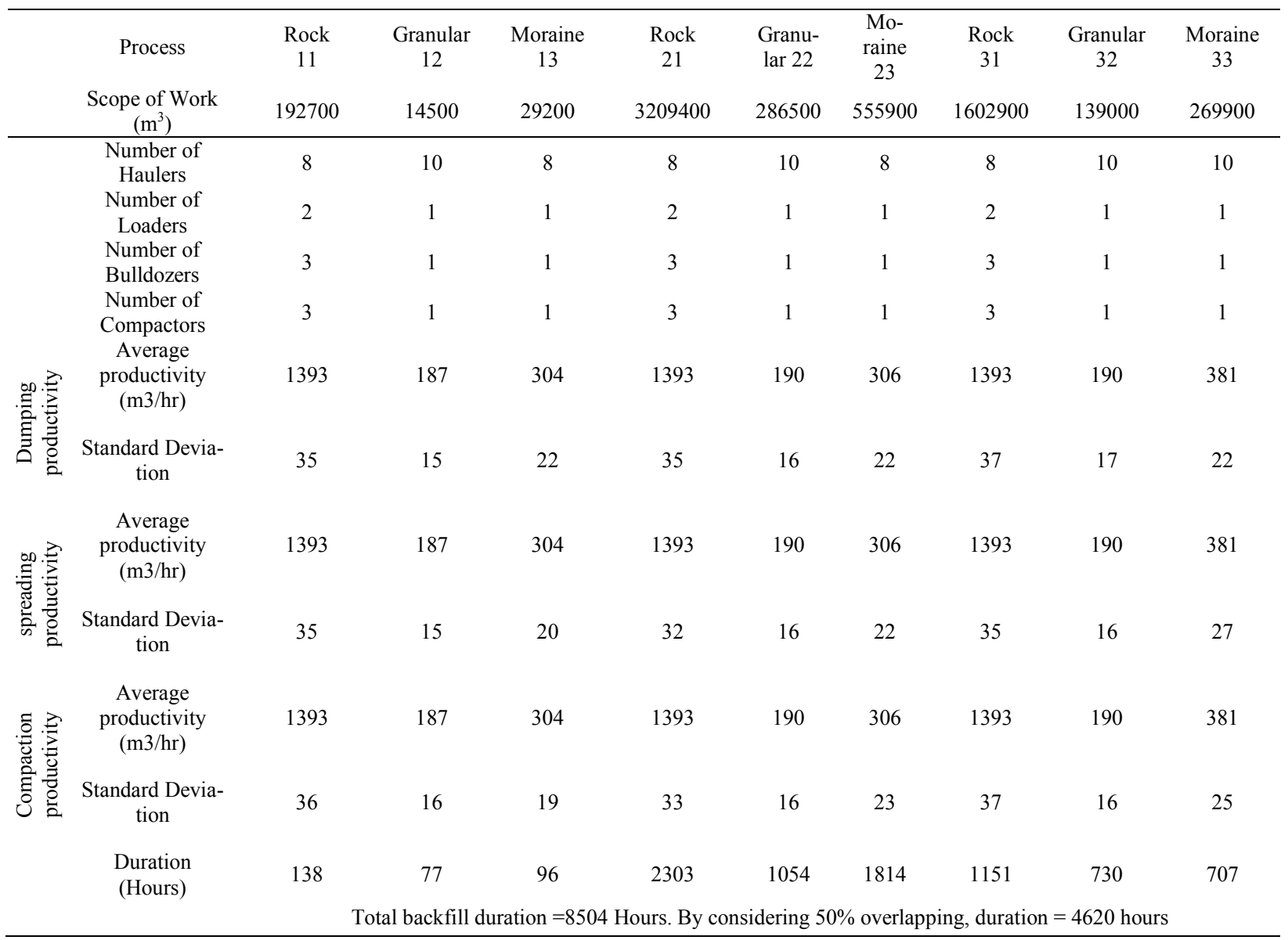

The fluctuation in productivity rate is attributed to the effects of factors considered in simulation process. Such factors are acknowledged by managers as high-risk for productivity rate and duration. However, in discrete simulation these factors are not accounted for. Yet the purpose of simulation model is to present an insight into the operations' interactions, and the utmost importance is to generate credible results. Since the FLDM represents near-real situation, its results were compared with actual project data. The real project completion was 7224 hours; the percentage of difference between the actual and the simulated duration was $7.4 \%$. Figure 5 demonstrates the cumulative productivity rate for dumping process and total work completed for the two models, BM and FLDM. 
Table 5: Comparison of operation durations.

\begin{tabular}{lcc}
\hline \multicolumn{1}{c}{ Operations } & $\begin{array}{c}\text { Durations Computed by } \\
\text { process Modeling (Hours) } \\
\text { BM }\end{array}$ & $\begin{array}{c}\text { Durations Computed by } \\
\text { Hybrid Modeling(Hours) } \\
\text { FLDM }\end{array}$ \\
\hline [Rock11] & 138 & 226 \\
[Granular12] & 77 & 156 \\
[Moraine13] & 96 & 112 \\
[Rock21] & 2303 & 3309 \\
[Granular22] & 1054 & 2244 \\
[Moraine23] & 1814 & 2608 \\
[Rock31] & 1151 & 1694 \\
[Granular32] & 730 & 1065 \\
[Moraine33] & 707 & 1026 \\
\hline
\end{tabular}
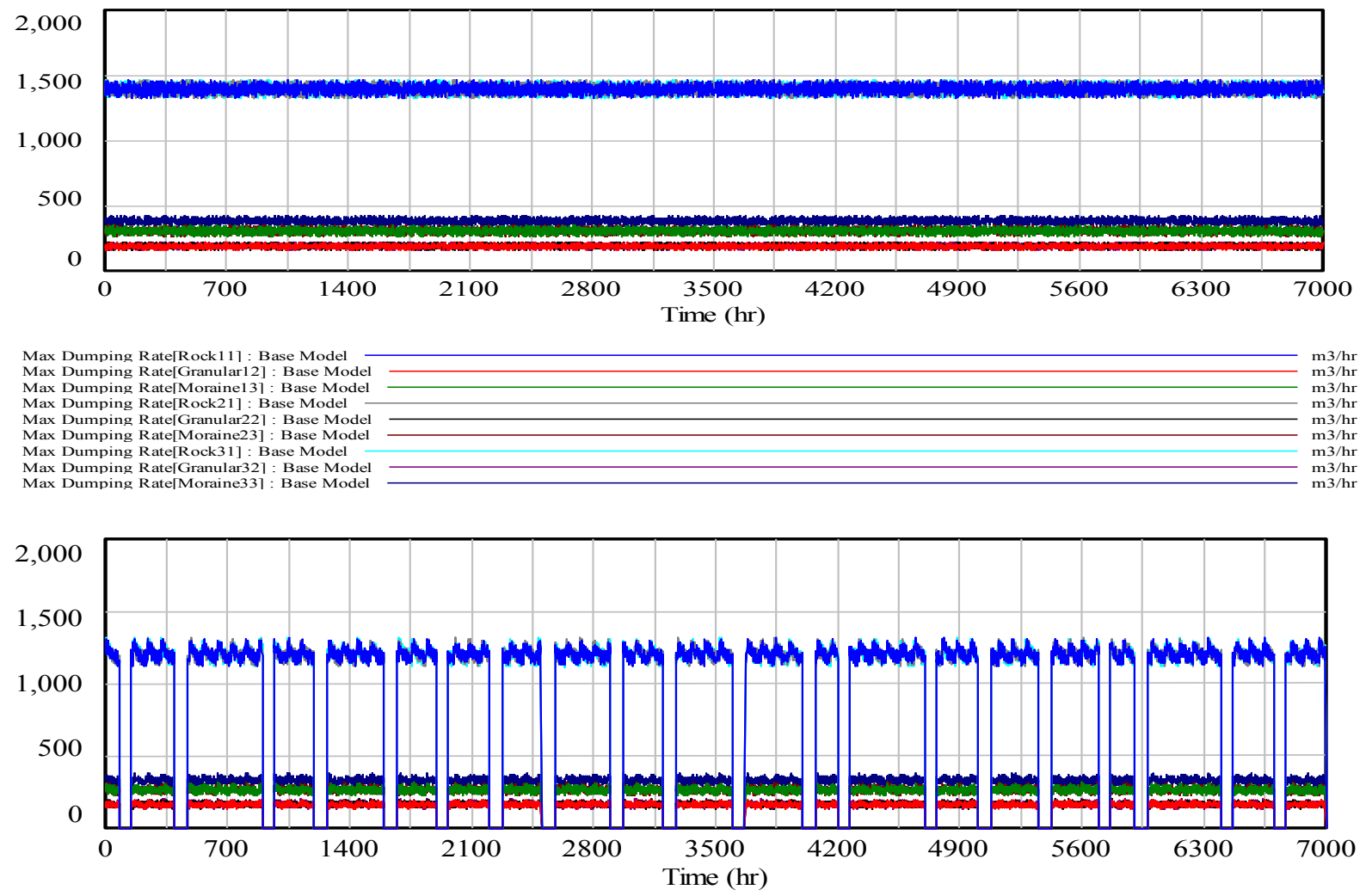

Figure 4: Productivity rate of dumping process under two situations. 
Total Soil Dumped

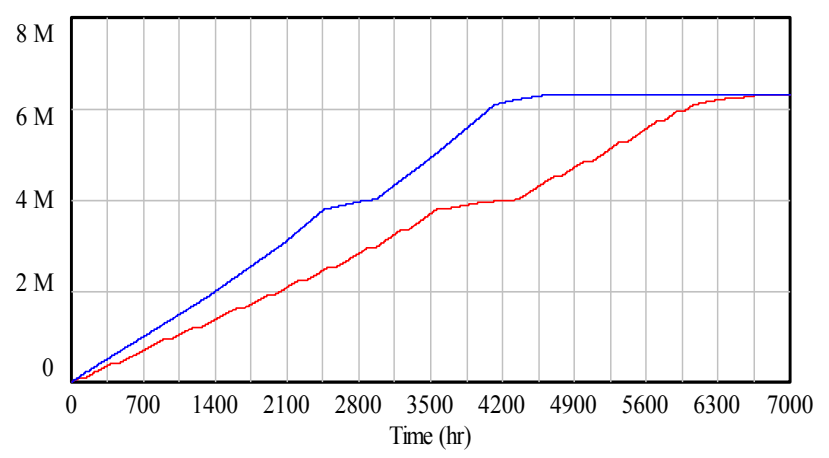

Total Soil Dumped : Base Case

Total Soil Dumped : Scenario B

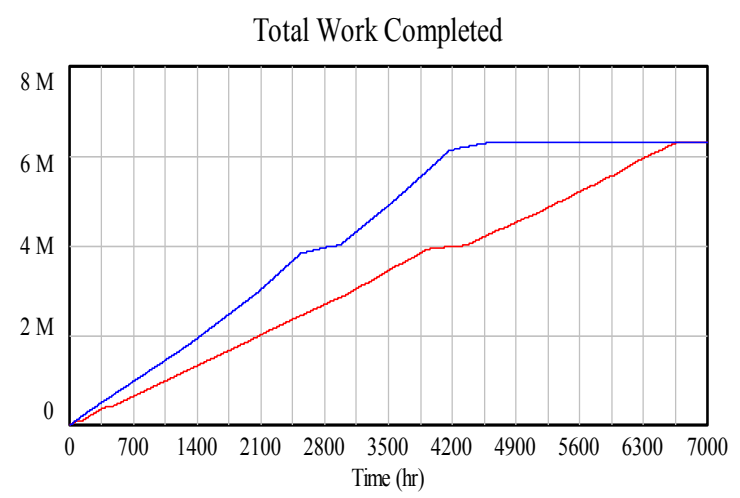

Total Work Completed : Factor Loaded Discrete Model
Total Work Completed : Base Model

\section{nis}

Figure 5: Release productivity outputs.

\section{CONCLUSION}

The purpose of simulating construction operations is to have an insight into the consequences of construction decisions. The utmost importance of simulation models is the credibility of results. Therefore, this paper presented an assessment to the outcomes of simulation models developed using different simulation methods. The assessment focused on the productivity rate and duration parameters. Discrete simulation is a form of process simulation that was deployed to calculate productivity rate and durations. However, such a technique generates ideal outcomes of the process or operation being simulated. This is because it tends to neglects the effects of influential factors that surround construction operations. Consequently, results generated from simulation models that are develop based on process approach provides misleading results and cannot be relied upon in decision-making process. In order to address this problem, the simulation approach called system modeling is considered to circumvent such limitations. It modeled the factors believed to affect process simulation model (quantifying $\mathrm{P}$ value) and inject their influence in the model.

The presented concept is implemented using a real case study that involved earthmoving operations in a dam construction. The project was decomposed into two types of elements: 1) process model elements; and 2) system model elements. These two elements were modeled and simulated using DES and SD respectively. The DES model produced the BM set of outcomes while merging SD into DES produced the FLDM and resulted in impacted set of outcomes. The results generated by impacted simulation model have shown a significant variation from the base case one. An average of $37 \%$ increase in operation durations and $29 \%$ decrease in productivity rate have been noticed for this specific case. This percentage is candidate to be higher if more factors are added to the model. This puts more emphasis on reconsidering using simulation process approach especially for construction operations that involve high dynamics, feedback process, and interactions with external environment.

Extending efforts to understand characteristics of construction projects or operations and accounting for their influential elements are the most important stage in creating a reliable simulation model capable of mimicking reality. A number of important parameters are not accounted for through using process modeling. This might be acceptable in management fields that consider the context of operations not significant in the simulation process; however, construction industry behavior is mainly generated through interaction of processes with their context. 
Alzraiee, Zayed, and Moselhi

\section{ACKNOWLEDGMENT}

The authors would like to thank Natural Sciences and Engineering Research Council of Canada (NSERC) for funding and supporting the present research.

\section{REFERENCES}

AbouRizk, S. 2010. "Role of Simulation in Construction Engineering and Management." J. Constr. Engrg. and Mgmt. 126(10):1140-1153.

Alzraiee, H., O. Moselhi, and T. Zayed. 2012b. "Methodology for Synchronizing DES and SD Models." In Proceedings of the 2012 Winter Simulation Conference, edited by C. Laroque, J. Himmelspach, R. Pasupathy, O. Rose, and A.M. Uhrmacher, 1-11. Piscataway, New Jersey: Institute of Electrical and Electronics Engineers, Inc.

Alzraiee, H., O. Moselhi, and T. Zayed. 2012a. "A Hybrid Framework for Modeling Construction Operations Using Discrete Event Simulation and System Dynamics." In Proceedings of Construction Research Congress, edited by H. Cai, A. Kandil, and P. Dunston, 1063-1073. Construction Institute (CI) of ASCE; Division of Construction Engineering and Management of Purdue University.

Banik, G.C. 1999. "Construction Productivity Improvement." In Proceedings of the Associated Schools of Construction (ASC) $35^{\text {th }}$ Annual Conference, edited by C. Berryman San Luis Obispo and Calif, 165-178. Fort Colo: Colorado State University.

Caterpillar Inc. 2012. "Caterpillar Performance Handbook." 42nd ed. Peoria, Illinois: Caterpillar Inc.

Choy, E., Y. R. Janaka, and Y. Ruwanpura. 2006. "Predicting Construction Productivity Using SituationBased Simulation Models." Canadian Journal of Civil Engineering 33:1585-1600.

Caterpillar Inc. 2010. “FPC user's Manual_Version 3.0.” Peoria, Illinois.

Howell, G.A., and L. Koskela. 2000. "Reforming Project Management: The Role of Lean Construction." In Proceedings of the 8th Annual Conference of International Group for Lean Construction (IGLC8), edited by J. Barlow, Brighton, UK: University of Sussex.

Huang, R., and D. W. Halpin. 1994. "Visual Construction Operation Simulation: the DISCO approach." J. Microcomp. in Civ. Engrg. 9(6):175-184.

Kamat, V. R., and J. C. Martinez 2001. "Visualizing Simulated Construction Operations in 3D." Journal of Computing in Civil Engineering 14(4):329-337.

Martinez, J. 1996. "Stroboscope: State and Resource Based Simulation of Construction Processes.” Ph.D. Dissertation, Civil Engineering Department, University of Michigan, Michigan, MI, USA.

Tucker, S. N., P. J. Lawrence, and M. Rahilly. 1998. "Discrete-Event Simulation in Analysis of Construction Processes." CIDAC Simulation Paper, Melbourne, Australia.

\section{AUTHOR BIOGRAPHIES}

HANI ALZRAIEE is a Doctoral candidate in Department of Building, Civil, and Environmental Engineering at Concordia University in Montreal, Canada. He holds a M.S. degree in Construction and Project Management and B.E. in Civil Engineering. Mr. Alzraiee has 10 years of professional experience in building and infrastructure design and project management. He is currently a research assistant at the Construction Automation Lab at Concordia University. His current research focuses on hybrid discrete event simulation and system dynamics integration for modeling and simulating construction operations on a single platform. In addition, he is working on research projects for assessing the trenchless rehabilitation methods used to rehabilitate Quebec's Province Sewer System. His email address is hani.alzraiee@concordia.ca.

TAREK ZAYED Dr. Zayed is an Associate Professor, Dept. of Building, Civil \& Environ. Eng., Concordia University, Montreal, Canada. Dr. Zayed has a Ph.D., M.Sc., and B.Sc. in Construction Engineering and Management. He conducted research in infrastructure management, simulation and AI applica- 
tions in construction, underground system performance, and life cycle cost analysis. He has 22 years of professional experience working in the construction industry training and in academic posts in USA, Canada and abroad. Dr. Zayed is extending his expertise in infrastructure management systems to develop life cycle cost analysis for constructing and rehabilitating highway, water, and sewer systems. In addition, he developed models that optimized budget allocation and risk assessment for infrastructure systems. His email address is tarek.zayed@concordia.ca.

OSAMA MOSELHI Dr. Moselhi is Professor of Engineering in the Department of Building, Civil and Environmental Engineering at Concordia University. He served as Department Chair and Executive Advisor to the Dean of the Faculty in graduate studies and research and in planning and appraisal of graduate programs. Since joining Concordia in 1985, after a decade of industry experience, Dr. Moselhi supervised and co-supervised over 50 Masters and Ph.D. graduates, authored and co-authored over 300 scientific publications. His industry experience spans tall buildings, bridges, harbor facilities, and nuclear power plants. He is recipient of numerous honors and awards; including the prestigious Walter Shanly Award in recognition of "outstanding contributions to the development and practice of construction engineering in Canada" Dr. Moselhi served as international consultant on academic affairs and on construction projects in Canada, USA, and the Middle East. His research interest encompasses planning, procurement, resource allocation, tracking and control of construction projects, with a focus on risk management, productivity analysis, management of construction claims and development of decision support systems embracing information technology, remote sensing, web-enabling and spatial technologies. His email address is moselhi@cbs-engr.concordia.ca. 